\title{
Can children with a psychiatric disorder be treated in a general ward?
}

\author{
ANNETTE KOLIND， JASON MARATOS
}

\begin{abstract}
Because admission to a regional child and adolescent psychiatric unit is often fraught with difficulties children with psychiatric disorders were admitted to a general children's ward. Over the four years (1980-4) 24 patients accounted for 31 admissions. Of these, five had feeding disorders (anorexia, bulimia), seven neuroses, three psychoses, four elimination disorders, and five other diagnoses. All the children were later discharged to their homes, most having appreciably improved. Because of the proximity of the hospital to the child's natural environment work with the families and schools was not interrupted by the admission. The results of this approach are encouraging and could have implications for future planning of services for this category of patients.
\end{abstract}

\section{Introduction}

We review our experience of children with a psychiatric disorder admitted to the children's ward of a district general hospital.

\section{Patients and methods}

Only children who needed admission to hospital and who would not be a threat to physically ill children were admitted after consultation between the psychiatrist and the sister in charge. The children were admitted for three main reasons: (1) because they could not be contained in the community (for example, psychotic children, anorexic, severely obsessional), (2) in order to implement a therapeutic programme that could not be implemented at home (for example, for elimination disorders, anorexia, etc), and (3) to assess diagnostic problems.

The ward had 21 children's beds, nine of which were in separate cubicles, with an additional bed for mother. The children stayed in hospital during nights and weekends initially, but flexible arrangements could be made for each child to spend time at home according to his needs. The paediatric senior house officer provided first cover, and the consultant psychiatrist was on call.

\section{HISTORY}

Amersham General Hospital was one of the first hospitals in England, in 1950 , to institute rooming in for mothers; the film "Going to hospital with mother" was made here. ${ }^{1}$ The tradition that was started by the paediatrician, Dr Dermod MacCarthy, has been continued by Dr Donald Garrow and is currently kept alive by the present paediatricians (Drs Cheetham and Fleet) and ward sister Jenny Gilbert.

The nurses and the other staff (ward play leaders, ward teacher, paediatric social worker) have a positive attitude towards emotionally disturbed children and have always welcomed a close cooperation with the child psychiatrist.

\section{Results}

In the four years, June 1980 to May 1984, there were 31 admissions of 24 patients ( 14 girls, 10 boys; age range 3-18 years (mean 13 years 1 month)) to

\section{Child and Family Guidance Clinic, High Wycombe, Bucks}

A KOLIND, MD, registrar in child psychiatry

J MARATOS, MPHIL, MINSTGA, consultant child psychiatrist

Correspondence to: Dr A Kolind, 56 Amersham Hill, High Wycombe HP13 6PQ. the children's ward at Amersham General Hospital after referral from the Child and Family Guidance Clinic in High Wycombe (table I). Four girls and one boy were admitted twice and one girl three times. Under the age of 12 years boys accounted for all admissions, whereas more girls were admitted over 12 years. This is consistent with a reversal of the sex ratio in psychiatric disorders during adolescence. ${ }^{2}$

TABLE I-Age and sex distribution of children on admission

\begin{tabular}{lllllllllllllll}
\hline \multicolumn{1}{c}{ Age (yr): } & 3 & 4 & 5 & 6 & $7-9$ & 10 & 11 & 12 & 13 & 14 & 15 & 16 & 17 & 18 \\
\hline Boys & 1 & 2 & 2 & 1 & 0 & 1 & 0 & 1 & 0 & 2 & 0 & 0 & 1 & 0 \\
Girls & 0 & 0 & 0 & 0 & 0 & 0 & 0 & 7 & 3 & 1 & 2 & 2 & 4 & 1
\end{tabular}

The admissions lasted between one day and two and a half years with a median of 20 days (table II). Most admissions (17) lasted less than three weeks, 10 admissions lasted between three and 12 weeks, whereas two lasted between 13 and 17 weeks. The two anorectic girls who stayed for eight months and two and a half years are shown with a duration $>18$ weeks.

TABLE II-Duration of admission according to sex

\begin{tabular}{lccccccccccccc}
\hline Duration (weeks): & $\leqslant 1$ & 2 & 3 & 6 & 7 & 8 & 9 & 10 & 11 & 12 & 14 & 17 & $>18$ \\
\hline Boys & 2 & 0 & 3 & 2 & 1 & 0 & 1 & 1 & 1 & 0 & 0 & 0 & 0 \\
Girls & 3 & 5 & 4 & 0 & 0 & 1 & 0 & 2 & 0 & 1 & 1 & 1 & 2
\end{tabular}

Table III shows the diagnoses on discharge, which were classified according to the first axis of Rutter's multiaxial classification. ${ }^{3}$ The group with psychoses included one child with schizophrenia, one with depressed type of manic depressive psychosis (both admitted twice), and one with nonorganic psychosis of depressed type (ICD-9 classification: 298.0). The group with neurotic disorders included one child with anxiety state, four with hysteria, one with neurotic depression, and one with obsessive compulsive disorder (admitted twice). The feeding disorders included four girls with anorexia nervosa, one of whom had three admissions, and one girl with bulimia nervosa. The elimination disorders included two boys with enuresis, one boy with encopresis, and one girl with frequency of micturition (ICD-9 classification: $306 \cdot 5)$.

TABLE III-Diagnoses on discharge. Figures in parentheses are number of admissions

\begin{tabular}{llccc}
\hline \multicolumn{1}{c}{ Diagnosis } & ICD-9 classification & Girls & Boys & Total \\
\hline Psychosis & $295,296,298$ & $3(5)$ & $0(0)$ & $3(5)$ \\
Neurotic disorder & 300 & $3(3)$ & $4(5)$ & $7(8)$ \\
Feeding disorder & $307 \cdot 1,307 \cdot 5$ & $5(7)$ & $0(0)$ & $5(7)$ \\
Elimination disorder & $307 \cdot 6,307 \cdot 7,306 \cdot 5$ & $1(2)$ & $3(3)$ & $4(5)$ \\
Conduct disorder & 312 & $0(0)$ & $1(1)$ & $1(1)$ \\
Adjustment reaction & 309 & $1(2)$ & $1(1)$ & $2(3)$ \\
Disturbance of emotions & 313 & $1(1)$ & $0(0)$ & $1(1)$ \\
Disturbance of activity and attention & 314 & $0(0)$ & $1(1)$ & $1(1)$ \\
\hline \multicolumn{1}{l}{ Total } & & $\mathbf{1 4 ( 2 0 )}$ & $10(11)$ & $24(31)$
\end{tabular}

ICD = International Classification of Diseases.

One clinic professional was required in the care of four children, two with 13 , three with 10 , and four with four during the admissions in addition to the ward staff. Thus two or three professionals were involved in most cases; these included a psychiatrist ( 31 cases), a registrar ( 16 cases), a social worker (18 cases), an educational psychologist (nine cases), and a psychotherapist (three cases). The consultant child psychiatrist was naturally concerned with all cases, but the involvement of the others depended on each individual 
case. The treatment during admission consisted of one or more of the following: milieu therapy, family therapy, individual psychotherapy, behaviour modification programmes, and pharmacotherapy.

Discharge was part of a planned reintegration programme. The children were able to attend their ordinary school while in hospital and could also spend an increasing amount of time at home until they were ready for discharge. Table IV shows the outcome on discharge from hospital. A six

TABLE IV-Outcome on discharge from hospital

\begin{tabular}{lc}
\hline \multicolumn{1}{c}{ Outcome on discharge } & No of children $^{\star}$ \\
\hline Worse & $0(0)$ \\
No change & $0(3)$ \\
Slightly improved & $4(4)$ \\
Improved & $5(7)$ \\
Much improved & $9(10)$ \\
Recovered & $6(7)$ \\
\hline
\end{tabular}

${ }^{\star}$ Number of admissions in parentheses.

step grading was used to describe the change of the symptoms and behaviour between first admission and final discharge from hospital. None of the children got worse. The three children with no change on discharge were all readmitted later, but they all improved on subsequent admission. Slight improvement was seen in four children, all of whom continued to receive some kind of psychiatric help from the clinic or other hospitals. Even though the results were encouraging in the rest of the cases, contact with most of the children continued, except for five, two of whom moved out of the area and three who were treated elsewhere (by another psychiatrist, as a planned admission to another hospital for treatment of bulimia, and by a general practitioner who was happy to continue on his own without the help of the child guidance team).

The help offered to the families after discharge from hospital included family therapy, individual psychotherapy combined with support for the parents, continued control and adjustment of pharmacotherapy, behaviour modification programmes, and attendance of the child at the educational therapy unit, a day unit for school children with emotional and behavioural difficulties.

\section{Discussion}

The present five child and adolescent psychiatric beds at Amersham General Hospital have been used mainly for children with acute psychoses (schizophrenia, manic depressive psychosis) and anorexia nervosa. To a lesser degree they have been used by children in crisis. They are considered to be acute psychiatric beds for treating severe disturbance. Children with emotional and conduct disorders, who form $70 \%$ of admissions to other inpatient units, ${ }^{45}$ are mainly treated as outpatients in our district.

No injuries were caused by our patients in the ward to other patients or staff. Treating these children in the ward has been surprisingly uncomplicated. Disturbed behaviour was effectively handled with sensitivity and care by the staff. Examples of potentially unsettling behaviour occurred when a schizophrenic girl was posturing nude in her cubicle, when another deluded girl was expressing her conviction that the ward was on fire, and when an obsessional teenager refused to be separated from his mother. On no occasion did a child hurt or interfere with the treatment of another. We did not notice that the presence of physically ill children and the occasional death of a child appeared to have a damaging effect on any of our patients.

We consider that the admission of children with a psychiatric disorder to a general children's ward is an extremely useful addition to the facilities offered in our district. It provides care that is flexible, immediate, and in close proximity to the child's natural environment. It also provides continuity of care, so that the admission to hospital represents only a period in the total treatment of a child. The child does not have to be passed on when his condition deteriorates, and when he is better he does not have to be separated from the team who looked after him when his illness was at a more serious stage.

The ward has the usual staff complement for a paediatric ward in a district general hospital-namely, sisters and nurses (State $\underset{\sim}{\square}$ Registered Nurses or Registered Children's Nurses or both), $\frac{3}{\Phi}$ playleaders, a teacher, a paediatric social worker, trainee doctors, $\stackrel{\AA}{\varrho}$ and student nurses. Some of the trainee doctors are part of a general $c$

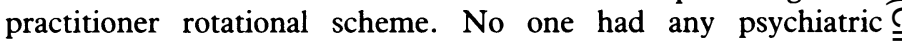
qualifications.

A determined effort was made to train the staff of the children's ward through seminars, weekly workshops, and thorough discus- $\$$ sion of cases. The training that the ward staff receives by treating $\varrho$ severely disturbed children has a positive effect on their treatment of physically ill children and makes the ward staff ideally equipped $\stackrel{\vec{\rho}}{\rightarrow}$ for coping with psychosomatically ill children. The trainee doctors $\overline{0}$ found this experience particularly relevant to their future work in practice.

The possibility of a gradual reintegration of the child into the $\overparen{\Phi}$ community is an important aspect. The child can start attending his ordinary school while in hospital, continue seeing his natural ${ }^{\infty}$ friends, and spend an increasing amount of time at home before $\vec{\circ}$ discharge. Younger children had no difficulties in finding a peer $\overrightarrow{\vec{H}}$ group. Because the number of adolescents in the ward at any one time $\underset{\sigma}{\omega}$ was small they had less opportunity for peer interaction than they would have had in a regional unit. Nevertheless, they made up for this by relating to the student nurses who were of comparable age.

We do not suggest that this kind of approach can replace regional units, but we consider that it is a useful addition to the existing services. The results of this approach are encouraging and could have implications for future planning of services for this category of $\mathrm{N}$ patients.

\section{References}

1 Robertson J. Going to hospital with mother. New York: New York University Film Library, 1958. 2 Department of Health and Social Security. Health and personal social services statistics for England. London: HMSO, 1979.

3 Rutter ML, Shaffer D, Sturge C. A guide to a multiaxial classification scheme for psychiatric disorder in childhood and adolescence. London: Institute of Psychiatry, 1975.

4 Barker P, Jamieson R. Two years' admissions to a regional child psychiatry unit. Br Med 1967;ii: 103-6.

5 Mathai J, Lewis C. Review of 15 years' admissions to a regional child psychiatric unit. ACPP Newsletter 1983; No 16:2-6.

(Accepted 4 April 1985) syndrome. Two months ago she started complaining of an uncomfortable feeling of "fullness" in her neck and upper chest, which her cardiologist has attributed to jugular reflex. What is this phenomenon and how might her symptoms be alleviated?

The VVI pacemaker provides the most common form of pacing $T^{\text {namely, }}$ 응 ventricular inhibited pacing. Some patients tolerate this form of pacing less well than others, however, and an entity known as pacemaker's syndrome $\sigma$ may ensue. This is characterised by dizziness, fatigue, palpitations, and $D$ periods of hypotension. Any or all of these symptoms may be present, and they may arise by the following mechanisms: (1) a reduction in the force of $\mathrm{N}$ left ventricular contraction associated with a loss of the atrial contribution to $N$ left ventricular end diastolic volume and pressure; (2) atrioventricular $\omega$ dissociation in which contraction occurs while the atrioventricular valves are closed thus giving rise to atrial distension which may cause a feeling of 0 fullness in the neck and perhaps, through atrial reflexes, predisposes to $\mathbb{D}$ hypotension; (3) ventriculoatrial conduction of the paced ventricular $\stackrel{\mathscr{S}}{+}$ impulse may coincide with contraction of the atria against closed atrio- $\square$ ventricular valves, which provides another mechanism by which venous $\bar{O}$ distension and reflex hypotension may occur. This syndrome occurs most $\mathbb{D}$ frequently in patients with a deficient myocardium but this is not always so. A change in pacing mode to dual chamber pacing or atrial pacing where the integrity of the AV-node is proved to be intact may help.-JOHN H HORGAN, consultant cardiologist, Dublin.

Miller M, Fox S, Jenkins R, Schwartz J, Toonder FG. Pacemaker syndrome: a non-invasive means to reach diagnosis and treatment. Pace 1981;4:503-6.

Nishimura RA, Gersh BJ, Vlietstra RE, Osborn MJ, Ilstrup DM, Holmes DR. Haemodynamic and symptomatic consequences of ventricular pacing. Pace 1982;5:903-10.

Panidis I, Dreifus LS, Michelson EL. Haemodynamic effects of cardiac pacing. In: Dreifus LS, ed.

Pacemaker therapy. Cardiovasc Clin 1983;14:1-11. 